\title{
A volta do papel das crianças no contrato geracional $^{*}$
}

\author{
JENS QVORTRUP \\ Norwegian University for Science \\ and Technology \\ Tradução de Maria Letícia Nascimento \\ Revisão Técnica de Ana Canen
}

\section{ALGUMAS PALAVRAS À GUISA DE INTRODUÇÃO}

Ao contrário da maioria dos observadores, estudiosos, políticos e adultos em geral que veem as crianças como seres frágeis, no presente artigo argumento que elas são - e historicamente sempre foram - participantes úteis à sociedade. Acho pertinente a este Congresso de Educação lembrarmos que mesmo o trabalho escolar realizado pelas crianças tem utilidade, pois, sem ele, nossa sociedade moderna não poderia sobreviver. Destacarei, sobretudo, a ligação de crianças com idosos, por intermédio do cuidado desses, destacando, pois, seu papel na manutenção do contrato entre gerações.

\section{AS CRIANÇAS E OS APOSENTADOS}

Praticamente todos os países desenvolvidos demonstram preocupação com o envelhecimento de sua população. A mídia, a política e a ciência têm levantado

* Artigo apresentado na sessão especial "Educação na infância: perspectivas históricas, sociológicas e políticas”, na 33a Reunião da ANPEd, Caxambu, em outubro de 2010. 
questões sobre suas causas. Mesmo que não haja pleno acordo, dificilmente se poderá negar a realidade de que o principal fator por trás do envelhecimento é a taxa de fertilidade decrescente ao longo da maior parte do século XX.

São claras as divergências sobre como abordar o envelhecimento da população. Os políticos parecem preferir soluções fragmentadas de curto prazo em detrimento das de longo prazo, uma vez que, do ponto de vista ideológico, estas poderiam resultar em decisões impopulares e sensíveis. Em princípio, duas possibilidades estariam disponíveis para garantir aposentadorias e cuidados aos idosos, são elas: aumento da imigração e da fertilidade. Nenhuma dessas alternativas é politicamente fácil de ser alcançada.

Deixarei de lado a imigração e focalizarei somente o fator natalidade. Neste sentido, os dois principais elementos deste breve artigo podem ser introduzidos, a saber: o envelhecimento de nossa população e a escassez de crianças. Não pretendo desenvolver um debate ideológico em torno do apoio à fertilidade. Pretendo, isso sim, apresentar uma fundamentação histórica e lógica que sustenta o argumento de que a velhice e a infância estão inter-relacionadas e de que, nessa perspectiva, é pertinente falar em contrato entre gerações. Em resumo, a tese que aqui defendo poderia ser a de que sem filhos, não há aposentadorias! A presente exclamação parece um tanto trivial e talvez pudesse ser mais bem compreendida a partir da seguinte questão: Por que houve desequilíbrio no desenvolvimento populacional e, em particular, por que a fertilidade tem atingido, em toda a Europa, nível de reposição abaixo do esperado? Argumento que isso se dê porque as crianças deixaram de ser vistas como parte do contrato entre gerações. E por que foram excluídas como atores positivos da equação geracional e como poderíamos trazê-las de volta?

\section{DO PACTO GERACIONAL AO CONTRATO}

Um pacto geracional é, em sua forma tradicional, um acordo não escrito sobre formas pelas quais obrigações e recompensas são distribuídas entre gerações. Historicamente, a reciprocidade entre elas, em termos de obrigações mútuas, tem prevalecido: a geração média de adultos não só provê e cuida de seus filhos, mas também de seus pais idosos. Até o início do século XIX, as crianças começavam a trabalhar tão logo tivessem condições para tal e, no devido tempo, tinham de cuidar de seus próprios idosos, como adultos. Essa regra era praticamente universal. Quem não tinha filho era percebido como desprovido de um papel ativo nos esforços comuns da comunidade, colocando em risco a possibilidade de receber provisão financeira e cuidados. Naturalmente, esse sistema pouco sentimental raramente funcionava sem tensões, mas era um modelo aceito por todos. Tal sistema de autorregulação foi rompido e perdeu sua transparência com a industrialização e outros fenômenos relacionados, como a urbanização, a ascensão da classe operária, a ideologia familiar e a transição demográfica. 
Para meu propósito, gostaria de argumentar que, como parte desse desenvolvimento, o trabalho infantil clássico foi substituído pela escolarização, foram introduzidos os regimes de aposentadoria e outras políticas sociais foram criadas, de modo que se promovessem redes alternativas de segurança para as famílias. Essas mudanças praticamente acabaram com as clássicas motivações para a fertilidade, entre elas o reconhecimento das crianças como contribuintes ativos e, em particular, a expectativa de que, na velhice, os pais receberiam provisões e cuidados por parte delas, assim como seus ascendentes adultos. Poderíamos então sugerir que, ao longo do século, quando as crianças trocaram as tarefas obrigatórias, passando do trabalho manual para o trabalho escolar, fora iniciado o processo de redução da fertilidade.

De acordo com essa perspectiva, a transformação de maior amplitude foi a separação entre os processos de produção e de reprodução, que antes ocorriam no mesmo lugar, ou numa vizinhança alargada. De fato, como resultado do processo de industrialização, a reprodução passou a ser atribuída à família nuclear (não mais uma "família extensa", autossustentável), enquanto a produção passou a ser etapa externa a ela. A reciprocidade intergeracional, que até então era bem compreendida, tornou-se obscura: as transações econômicas não ocorriam mais dentro do sistema familiar ou de parentesco, mas de uma forma despersonalizada entre as gerações, em nível da sociedade mais ampla (o chamado sistema de contribuição previdenciária). ${ }^{1}$ Essas mudanças aconteceram em meio a profundas alterações, não necessariamente intencionais, no que diz respeito à responsabilidade e à solidariedade intergeracional. No entanto, a diminuição da fertilidade juntamente com a consolidação da família nuclear passaram a definir a possibilidade de uma nova constelação de famílias sem filhos. Na Escandinávia atualmente apenas cerca de 25\% das famílias têm obrigações cotidianas para com as crianças. Embora todas vivam em lares nos quais os adultos compartilham a renda com elas, aqueles sem filhos (os restantes 75\%) são livres para gastar seus rendimentos sem quaisquer obrigações para com as crianças. Uma consequência disso é que o risco de a criança pertencer a uma família relativamente pobre se tornou maior (Coleman, 1990, p. 590).

Uma crítica relativa a essa transformação é a de que as motivações para a fertilidade se perderam. Ao mesmo tempo em que os pais continuam sendo responsáveis pelas principais despesas para com a educação das crianças, a sociedade em geral, e a sociedade empresarial em particular, permanecem como os principais beneficiários dos investimentos que os pais realizam. Assim, considero que o faux pas mais gritante foi este: o que se pode esperar de um sistema, em termos de possiblidade de sobrevivência a longo prazo, quando aqueles que nele investem não se beneficiam dele, ao passo que aqueles que se beneficiam são justamente os que não investem?

1 No original, Pay-as-you-go pension system. (N. do T.) 
Para dizer de outra maneira: os investimentos da família nas crianças, em termos de tempo e dinheiro, representam contribuição considerável para a sociedade empresarial (em termos de força de trabalho futura) e para sociedade em geral (em termos de geração de recursos para pensões e aposentadorias, em especial). Essa evolução tem sido notada tanto por economistas feministas (Folbre, 1994; Bojer, 2000, p. 25), como por pensadores conservadores (como Kaufmann, 2005), que argumentam pela demanda, ao menos para as mães, por compensação de gastos por rendas não recebidas (os custos de oportunidade).

Ao mesmo tempo em que, dos pontos de vista lógico e moral, tal demanda parece ser plenamente justificada, é sintomático que a participação das próprias crianças seja pouco reconhecida nesse contexto. Kaufmann (2005) sugere que a transição para a sociedade industrial teve, como consequencia, o fato de o Estado apropriar-se, no lugar dos pais, do trabalho das crianças. As crianças, segundo esse ponto de vista, passaram a frequentar a escola, e seus pais não puderam mais se beneficiar de seu trabalho.

Neste artigo, defendo a ideia de que o Estado tem tomado para si o trabalho e/ou o tempo das crianças. Em outras palavras, atribuo às crianças o status de sujeitos e, como tal, de atores sociais que necessitam de compensação. $\mathrm{O}$ fato de a remuneração real ir para os pais ou para as próprias crianças não está em questão aqui; trata-se apenas de demonstrar - histórica e logicamente - que as crianças são sujeitos ativos e, portanto, estão produtivamente envolvidas no tecido social.

\section{CRIANÇAS COMO SUJEITOS DE VALOR SOCIAL}

Alguns (Bojer, 2000) têm argumentado a favor da obrigação moral de incluir as crianças em uma justa distribuição de recursos. Embora eu possa subscrever essa afirmação, pretendo avançar, postulando que as crianças, como resultado de seus próprios esforços, merecem ser contempladas com uma quota justa de recursos sociais. Meu argumento sustenta-se em duas razões: de um lado, pela ideia de que se deve fazer justica às crianças como participantes construtivos da sociedade; de outro, no intuito de demonstrar a continuidade histórica de sua participação.

A tese de que as crianças não pararam de trabalhar, apesar da transformação da sociedade no século XIX, vai contra a sabedoria convencional. "Alguém ainda tem a sensação de que as crianças em sociedades como a nossa são subempregadas", escreveu Boocock (1976, p. 424). Cunningham, historiador da infância, aponta o mesmo quando observa que, historicamente, o trabalho em geral se tornou cada vez mais “adultizado" (Cunningham, 2000). Além disso, devo reconhecer que foi a natureza do trabalho infantil que mudou, tornando-se invisível. O próprio trabalho se manteve, mas assumiu outra forma: a do trabalho escolar.

Essas citações tacitamente reforçam o fato de que as crianças, em épocas históricas anteriores, de fato trabalhavam. Para além das formas de exploração la- 
borial então existentes, parece haver concordância geral de que crianças e trabalho eram fenômenos conciliáveis nas sociedades pré-industriais. Nelas, os seres infantis eram unanimemente celebrados como membros úteis. Suas atividades podiam assumir várias formas, ${ }^{2}$ a depender do modo de produção, mas eram semelhantes no sentido de que, independentemente do lugar onde se desenvolviam, eram úteis ou funcionais à sociedade ou à cultura em que eram desenvolvidas. Em outras palavras, o trabalho infantil era imanente ao sistema. Essa utilidade foi reconhecida não só em termos do status atribuído às crianças que trabalhavam, mas também a partir dos elevados níveis de fertilidade verificados. Houve, pois, uma coincidência inegável entre o momento da transição demográfica e o aparecimento da escolarização em massa nas sociedades industrializadas. Como as atividades obrigatórias das crianças mudaram de manual para mental, os pais reduziram o número de crianças.

\section{TRABALHO INFANTIL COMO SISTEMA DE TRABALHO IMANENTE}

Nossa cultura é, sugiro eu, a primeira na qual as principais atividades infantis obrigatórias não são consideradas úteis e as crianças são desqualificadas, porque, em termos materiais, são membros não contribuintes da sociedade. Essa aberração deve alertar-nos para a necessidade de nos questionarmos em que medida seríamos culpados por uma interpretação errônea fatal. Essa culpa é, na verdade, difícil de ser admitida, uma vez que ocorre em um novo contexto de atitudes protecionistas em relação às crianças - ou nas palavras de Zelizer (1985) - no contexto da sentimentalização e da sacralização da infância. Em artigo escrito há quarenta anos, Martin Hamburger (1971, p. 1) colocou a questão da seguinte maneira:

A vida, o desenvolvimento e a saúde das crianças são, em geral, incomparavelmente melhores do que nunca antes na história. Ao mesmo tempo, a aplicação estrita de cuidados e atitudes de proteção em relação às crianças pode muito bem criar uma situação paradoxal em que a proteção significa exclusão e a exclusão significa privação [...] Cada vez mais, os humanistas reconhecem que o perigo da participação das crianças na economia deve ser colocado junto a outro risco: o de que as crianças não tenham um papel útil a desempenhar. (grifo do original)

Acredito que esse diagnóstico seja correto, ou seja, que a proteção às crianças e sua participação ativa na sociedade pareçam ser aspectos mutuamente excludentes.

2 As mudanças foram mais evidentes entre os meninos (caça, pesca, agricultura, fabricação ou qualquer produção de subsistência prevaleceu), enquanto as meninas ficaram, em sua maioria, na casa e na cozinha. Comum a ambos foi, contudo, sua utilidade, percebida pelos pais e localidades. 
Com a crescente proteção infantil, a não participação tornou-se uma virtude, mas a inutilidade foi vista como risco. ${ }^{3}$ Hamburger (1971) procurou dar uma solução a essa questão como proposta de que se fomentasse uma série de atividades relevantes, interessantes e promotoras do desenvolvimento infantil (idem, p. 5), denunciando " $a$ equação simplista entre o trabalho escolar e o trabalho produtivo" (idem, p. 1, grifo meu).

No entanto, esse é o ponto por onde, acredito, temos de começar a resolver a ambivalência apontada, solução esta que poderia partir do próprio subescrito de Hamburger. De fato, apesar de sua atitude positiva em relação à ideia de encarar a criança como participante ativa da sociedade, o autor parece alinhar-se com a maioria dos outros observadores ao omitir a maior parte das atividades desenvolvidas pelas crianças contemporâneas, notadamente seu trabalho escolar, deixando de encará-las em termos de importantes concepções de utilidade. Surpreende-me o fato de o trabalho escolar realizado por crianças em conjunto com seus professores ser sistematicamente ignorado como atividade útil.

Nesse ponto, indago: Como devemos entender o trabalho das crianças na escola? Acredito que, em primeiro lugar, tal trabalho representa uma continuidade histórica das noções de desempenho inerentes às atividades obrigatórias impostas por qualquer economia vigente. Dizer que as crianças sempre trabalharam não significa que tenham sempre trabalhado da mesma forma. Na verdade, tal feito teria sido surpreendente, levando-se em conta que as sociedades se modificaram em diferentes aspectos, a começar pelas formas de produção, no decorrer dos tempos. Além disso, a maioria dos observadores parece ter dificuldade em deixar de associar a ideia de trabalho infantil à de trabalho manual.

Com base no exposto, proponho uma generalização: de que a forma dominante do trabalho infantil seja sempre vista como sistema imanente, correspondente à forma de produção dominante. Antes do início da sociedade industrial, o trabalho manual foi a forma dominante, e apenas gradualmente o trabalho mental foi sendo incorporado, para assumir em seguida a hegemonia da concepção de trabalho na sociedade, sintomaticamente de forma paralela à escolarização em massa das crianças. Em outras palavras: embora o trabalho manual, em seu surgimento, estivesse em desacordo com o trabalho mental, creio que são semelhantes em termos de sua natureza imanente ao sistema ou, em termos de pesquisa comparativa, creio que podem ser considerados como tendo significados equivalentes.

A ideia de retratar as atividades escolares da criança como trabalho é contrária a nosso imaginário de infância, geralmente identificada como uma etapa de vida protegida. Na verdade, não que tais ideias sejam explicitamente opostas, mas a analogia entre elas parece nunca ter ocorrido à grande maioria das pessoas. Não se trata de mero acaso o fato de que nós, como atores da sociedade contemporânea,

3 Nesse ponto, o historiador Philippe Ariès (1962) parece concordar com Hamburger. 
solicitamos das crianças a realização de trabalhos escolares, em vez de trabalhos manuais. Fazemos isso porque nossa sociedade e nossos negócios necessitam da linguagem escrita, da alfabetização numérica e da perspicácia na linguagem da informática.

Não entrarei em detalhes para demonstrar como o trabalho escolar infantil é imanente ao sistema e, portanto, indispensável não só para a vida das crianças, mas também para a sociedade (para mais detalhes, consulte Qvortrup, 1995, 2000). Quero, ao contrário, argumentar que, para resgatar a decência na provisão do bem-estar social para os aposentados, devemos reverter a percepção comum de que as crianças não são parte integrante do contrato geracional. E como podemos trazê-las de volta? Não se trata de retornar aos velhos e bons tempos, mas de trazer os princípios da solidariedade intergeracional para dar suporte às circunstâncias modernas.

Em outras palavras, temos que tornar transparentes as seguintes ideias:

- qualquer economia dominante precisa do trabalho infantil imanente ao sistema;

- gerações posteriores sempre fornecem provimento financeiro àquelas que lhes antecedem.

A chave para resolver a atual situação das aposentadorias é deixar de punir os pais por ter tido filhos, filhos que, na situação atual, acabarão por beneficiar a sociedade em si. Temos de tornar plausível a ideia de que as crianças são um bem público e não meramente assunto privado. Embora seja verdade que, para os pais, as crianças permaneçam indispensáveis, do ponto de vista existencial e emocional, também se tornaram responsabilidade econômica para eles.

\section{A UTILIDADE DAS CRIANÇAS E O CONTRATO GERACIONAL}

Com base em evidências empíricas na Austrália, o demógrafo John Caldwell (1982) formulou a teoria sobre fluxos de riqueza entre gerações, argumentando tanto pela manutenção de elevados níveis de natalidade, como defendendo a ideia de que os fluxos intergeracionais de riqueza são positivos para pais e avós. Esse foi de fato o caso, como vimos, até o início da transição demográfica, no começo do século $\mathrm{XX}$. De acordo com essa linha de raciocínio, pode-se afirmar que as tradicionais motivações para a fertilidade foram extintas quando as crianças deixaram de ser vistas como ativo econômico, e o nexo econômico entre pais idosos e filhos adultos foi quebrado. Em outras palavras: o fluxo de riqueza entre gerações tornou-se negativo; ter filhos não tinha mais fundamentação econômica. A teoria de Caldwell sobre o fluxo de riqueza parece, portanto, ter sido confirmada.

No entanto, conforme poderia ser argumentado, tal perspectiva seria verdadeira apenas na medida em que aceitamos que a fertilidade e as crianças sejam vistas sobretudo como assuntos privados e finjamos que a economia da família permaneça 
dominante. $\mathrm{O}$ fato, porém, é que nada disso é verdade. As crianças são, como já foi dito (Folbre, 1994), um bem público; a economia dominante é hoje capitalista e altamente desenvolvida. Nesse contexto, o Estado, em nome do bem comum, tem a obrigação de tornar prósperos tanto a economia do país quanto o próprio povo. É sob essa nova realidade que o conteúdo do contrato geracional contemporâneo deve ser abordado. Tal realidade sugere que (1) o trabalho infantil não desapareceu, mas é imanentemente realizado sob um novo sistema, ou seja, por meio do trabalho escolar e, portanto, refere-se ao Estado e não à família como economia relevante; (2) não são mais as crianças biológicas que, pessoalmente, fornecem e cuidam dos pais idosos; é a geração posterior que provê as aposentadorias de todos os idosos - casais com ou sem filhos - por meio do chamado sistema de contribuição previdenciária.

As aparências poderiam fazer-nos acreditar em mudanças fundamentais. Entretanto, não é o que afirmamos no presente artigo, que postula, em última análise, que a continuidade reina sobre a aparência de diversidade. Afirmo que não ocorreram transformações fundamentais, nem a curto nem a longo prazo, em relação à utilidade das crianças. Em certo sentido, nos termos de Caldwell, o fluxo de riqueza continua a ser positivo, se compreendido do ponto de vista das gerações mais velhas. No entanto, para que essa perspectiva se concretize, devemos reconhecer que não somente os pais, mas também as crianças, contribuem para com o sistema:

- os pais, ao continuar investindo de forma desproporcional no país, se comparados tanto aos adultos cujos filhos não vivem com eles, como àqueles sem filhos;

- as crianças, por intermédio do trabalho escolar infantil que, durante sua realização, representa uma enorme e não remunerada participação infantil no tecido social, uma vez que os resultados desse trabalho serão visíveis no mercado algumas décadas mais tarde.

No desenho atual, os lucros dos pais e os investimentos das crianças são apropriados pela sociedade empresarial, pela sociedade em geral e pelos adultos sem filhos, embora o grosso das despesas permaneça com os pais. No entanto, esses lucros não são produtivos a longo prazo, já que favorecem o parasitismo e a desmotivação da reprodução, por parte dos adultos, em detrimento da rentabilidade a longo prazo da sociedade. Com base nas experiências históricas, também a economia moderna deve reconhecer a reprodução como indispensável para seu desenvolvimento. Nossa economia moderna é, provavelmente, a primeira na história a ignorar o fato de que a reprodução é condição sine qua non para sua sobrevivência, em consonância com a ideia de que os investimentos devem estar de acordo com os benefícios. Acho sensacional o fato de que a economia de mercado tenha de ser lembrada disso!

Os pais e os pais in spe devem, portanto, ter garantidas suas condições de vida para além da satisfação normativa e emocional, de modo que sejam motivados 
a contribuir para a reprodução da população da qual fazem parte. Para tal, trata-se de assegurar, para esses pais, um padrão de vida um pouco à frente daquele desfrutado por pessoas sem filhos. Como fazê-lo e implementá-lo é tarefa da administração política. Este artigo tem o mero objetivo de esboçar uma lógica histórica referente a relações justas, viáveis e duradouras entre as gerações. Pretende exatamente inserir as crianças em seu papel histórico como participantes e contribuintes da sociedade.

\section{REFERÊNCIAS}

ARIÈs, Philippe. Centuries of childhood: a social history of family life. Nova York: Vintage Books, 1962.

BoJer, Hilde. Children and theories of social justice. Feminist Economics, v. 6, n. 2, p. 23-39, 2000.

Bоососк, Sarane Spencer. Children in contemporary society. In: SкоLNick, Arlene (Org.). Rethinking vhildhood: perspectives on Development and Society. Boston: Little Brown \& Co., 1976. p. 414-436.

CAldwell, John C. Theory of fertility decline. Londres: Academic Press, 1982.

Coleman, James S. Foundations of social theory. Cambridge, Mass. and London: Belknap Press of Harvard University Press, 1990.

Cunningham, Hugh. "The decline of child labour: labour markets and family economies in Europe and North America since 1830". Economic History Review, vol. LIII, n. 3, p. 409-428, 2000.

Folbre, Nancy. Children as Public Goods. The American Economic Review, v. 84, n. 2, p. 86-90, maio 1994.

Hamburger, Martin. Protection from participation as deprivation of rights. New Generation, v. 53, n. 3, p. 1-6, verão 1971.

Kaufmann, Franz-Xaver. Schrumpfende Gesellschaft: Vom Bevölkerungsrückgang und seine Folgen. Frankfurt: Suhrkamp, 2005.

QVORTRUP, Jens. From useful to useful: the historical continuity of children's constructive participation. In: Ambert, Anne-Marie (Org.). Sociological Studies of Children, v. 7, 1995, p. 49-76.

. Verkennung und Kolonisierung der Schularbeit von Kindern: Ursachen und Folgen. In: Hengst, Heniz; ZeIher, Helga (Org.). Arbeit der Kinder. Weinheim: Juventa, 2000. p. 23-43.

Zelizer, Viviana A. Pricing the priceless child: the changing social value of children. Princeton: Princeton University Press, 1985. 
Jens Qvortrup

\section{SOBRE O AUTOR}

Jens QvorTRup é doutor em sociologia pela Universidade de Copenhagen. Professor do Departamento de Sociologia e Ciência Política da Norwegian University of Science and Technology (NTNU), em Trondheim, Noruega. E-mail: jens.qvortrup@svt.ntnu.no

Recebido em outubro de 2010 Aprovado em dezembro de 2010 


\section{A volta do papel das crianças no contrato geracional}

O artigo apresenta as relações entre as categorias infância, adultez e velhice, estabelecendo sua correlação econômica, política e social. Retoma a lógica histórica a respeito das relações sociais entre as categorias e discute as consequências do aumento do número de idosos em relação à escassez de crianças, apontando os riscos causados por esse desequilíbrio. Por meio do conceito de contrato geracional, destaca o papel do investimento nas crianças, e em seu trabalho escolar, como uma vantagem para a sociedade como um todo, uma vez que os resultados do trabalho serão visíveis posteriormente. A argumentação busca, sobretudo, inserir as crianças em seu papel histórico como participantes e contribuintes da sociedade.

Palavras-chave: infância; contrato geracional; participação social Bringing children's role back into the generational contract

The article presents the relationships among the categories of childhood, adulthood and old age, establishing economic, political and social correlations. It retraces the historical 
logic of the social relations among these categories and discusses the consequences of the increase of the elderly population and the decrease of the population of children, pointing out the risks that derive from this imbalance. Based on the concept of generation contract, it highlights the role of investing in children and in school work as a benefit for society at large, due to the visibility of the results of such work in the near future. The discussion attempts to embed children in their historical role as participants and contributors in society.

Keywords: childhood; generation contract; social participation

\section{El regreso del papel de los niños en el contrato generacional}

El articulo presenta las relaciones entre las categorías infancia, madurez y vejez estableciendo su correlación económica, politica y social. Retoma la lógica histórica sobre las relaciones sociales entre las categorias y discute las consecuencias del incremento del número de ancianos en relación a la escasez de niños, señalando los riesgos causados por ese desequilibrio. Por medio del concepto de contrato generacional, el estudio destaca el papel de la inversión en los niños y en su trabajo escolar, como una ventaja para la sociedad de manera general, una vez que los resultados de ese trabajo se harán visibles posteriormente. La argumentación procura, en especial, insertar a los niños en su papel histórico como participantes y contribuyentes de la sociedad.

Palabras clave: infancia; contrato generacional; participación social 